\title{
Assessing cardiac function in the single ventricle circulation: Kinetic energy ejection fraction
}

\author{
James Wong ${ }^{*}$, Radomir Chabiniok, Kuberan Pushparajah, Eva Sammut, Shane M Tibby, David Celermajer, \\ David Nordsletten, Daniel Giese, Tarique Hussain, Gerald F Greil, Tobias Schaeffter, Reza Razavi \\ From 18th Annual SCMR Scientific Sessions \\ Nice, France. 4-7 February 2015
}

\section{Background}

Those with single ventricle circulations often have a normal ventricular volumetric ejection fraction (VV EF) which is not in keeping with their symptoms and prognosis. Recently four-dimensional flow (4Dflow) magnetic resonance imaging (MRI) has been used to extract parameters of intra-cardiac kinetic energy (KE). There has been recent interest in measuring ventricular KE in health and disease to see if this could provide an additional tool in the assessment of ventricular function. We propose a new simple measure of ventricular function based on kinetic energy, the kinetic energy ejection fraction (KE $\mathrm{EF}$ ), and assess its usefulness in patients with single ventricle circulation.

\section{Methods}

Kinetic energy measured by 4D flow MRI was prospectively quantified in 41 patients with a single ventricle circulation (aged 0.5 - 28 years) and compared to 43 healthy volunteers (aged 1.5 - 62 years) who acted as negative controls, and 14 patients with left ventricular (LV) dysfunction (aged 28 - 79 years) who acted as positive controls. The ratio of ejected kinetic energy to total kinetic energy was used to devise KE EF.

\section{Results}

Figure 1 shows the MRI derived volumetric and kinetic energy parameters. The KE EF has a smaller range than VV EF in healthy subjects $(97.3+/-0.8 \%$ vs. $60.1+/-$ $5.5 \%)$. LV dysfunction causes a fall in KE EF $(90.0+/-$ 6.7; $p=0.0001)$. Although VV EF in healthy LVs and single ventricle hearts did not differ $(p=0.99)$ the respective KE EF was significantly lower $(91.0+/-8.0 \%$; $p<0.0001)$ with a wider range. Those reporting the greatest symptomatic impairment (NYHA II) had lower KE EF than asymptomatic (NYHA I) subjects ( $p=$ 0.0067) whilst in comparison VV EF remained unchanged $(p=0.54)$.

\section{Conclusions}

Kinetic energy parameters offer new insight into the function of the heart. KE EF is a marker of healthy cardiac function displaying a very small range of values in comparison to the broader range shown in VV EF. In those with single ventricle circulations it identifies a spectrum of diminished cardiac performance corresponding to a patient's perceived exercise tolerance. This is particularly useful in conditions such as single ventricle physiology where standard ejection fraction values are often normal.

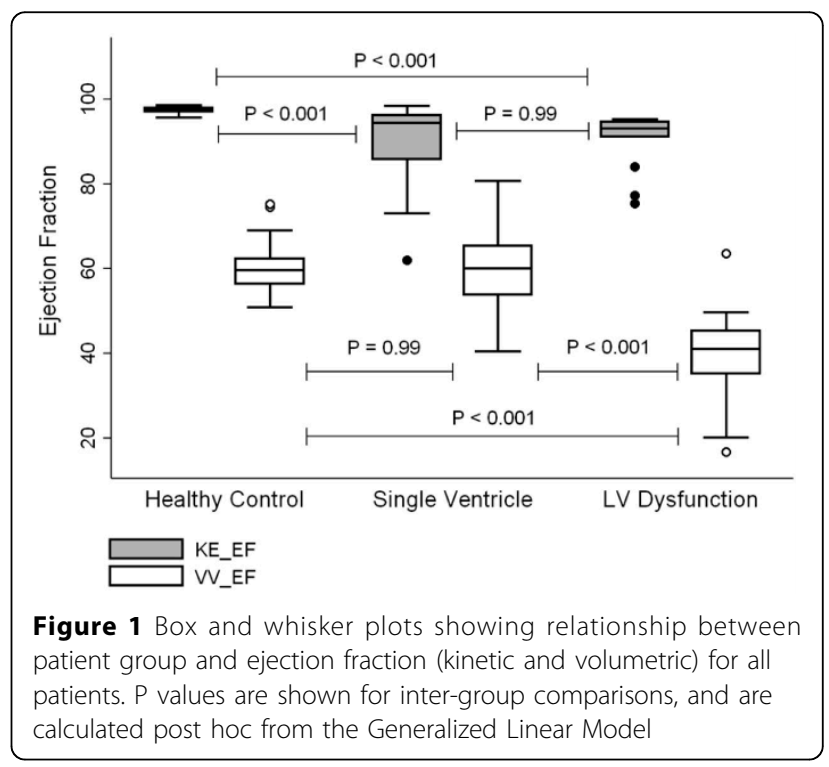


Further work to determine its relationship with other prognostic outcomes would allow full implementation as a clinical tool.

\section{Funding}

N/A.

Published: 3 February 2015

doi:10.1186/1532-429X-17-S1-057

Cite this article as: Wong et al:: Assessing cardiac function in the single ventricle circulation: Kinetic energy ejection fraction. Journal of

Cardiovascular Magnetic Resonance 2015 17(Suppl 1):O57.

Submit your next manuscript to BioMed Central and take full advantage of:

- Convenient online submission

- Thorough peer review

- No space constraints or color figure charges

- Immediate publication on acceptance

- Inclusion in PubMed, CAS, Scopus and Google Scholar

- Research which is freely available for redistribution

Submit your manuscript at www.biomedcentral.com/submit
Ciomed Central 